\title{
The 22nd International Congress of Historical Sciences Held in Jinan, China
}

\author{
LIU Jiafeng*
}

The 22nd International Congress of Historical Sciences was held in Jinan between the $23^{\text {rd }}$ and $29^{\text {th }}$ of August, 2015. This was the first time in its 115-year history that the Congress was held in Asia, outside of Europe or the so-called "Europeanized world." The Congress dates back to the International Congress of Comparative History held in Paris in 1900. Since then, the Congress has been held every five years (except during World Wars I and II); it is organized by the International Committee of Historical Sciences (CISH), which was founded in Geneva in 1926. The CISH is a non-governmental organization, established as an association for the promotion of the historical sciences through international cooperation. Being composed of 56 National Committees and more than 40 International Affiliated Organizations (e.g., the International Economic History Association and the International Federation for Research in Women's History), the CISH is the world's largest and most representative international academic organization in history. In 1938, Academia Sinica applied to join the International Committee of Historical Sciences as the Chinese National Committee, and sent Hu Shi to attend the 8th Congress in Zurich that same year. The Association of Chinese Historians officially became a National Committee of the CISH in 1982. The Congress was held in China in 2015 because Chinese historians have striven many years for dialogue and communication with academics from around the world. At the same time, the CISH has endeavored for many years to avoid Eurocentrism. As Robert Frank, Secretary-General of the CISH and Professor of Université Paris 1 Panthéon-Sorbonne, said, the Congress showed "how successful are the recent efforts of the historians to avoid Eurocentrism, to escape from a research too much centered on the Western point of view, to promote the Global and Transnational Turn... all issues very well represented in its programme." As one of the local organizers of Shandong University, I'd like here to make a brief sketch of the Jinan Congress.

* Liu Jiafeng 劉家峰 is head professor of Global History in the College of History and Culture, Shandong University. 
Ranking in the top 15 universities of China and continuously excelling in the fields of literature and history, Shandong University made considerable contributions to the preparatory work as the host of the Jinan Congress. All information was updated in time on the website: http://ichschina2015.org/ $\mathrm{cms} /$, including applications and registration information. Never have so many participants attended a Congress: 2,765 people registered on the website; 2,077 actually participated in the Congress in Jinan, including 785 foreign scholars from 76 countries and regions in Europe, America, Asia, Africa, and Oceania. Admirably, the host university provided accommodation for 124 scholars and plane tickets for 69 scholars, including junior scholars and scholars from developing countries.

The Congress consisted of different types of sessions: 4 Major Themes, 27 Specialised Themes, 18 Joint Sessions, and 19 Round Tables. In addition, 19 International Affiliated Organizations held their own special sessions, and 3 Evening Sessions and a Graduate-Student Poster Session were also included. Each session having been organized by scholars from at least two countries and papers presented by scholars from four or five different countries, the Congress was clearly international in reality as well as in name. The 2015 Joint Conference of the Committee of Teaching Guidance on History, under the Ministry of Education and Chairmen of History Departments in China, and The National Forum of the Post-Doctor of History, were parallel conferences also held in Jinan. Satellite conferences focusing on research of the Qilu Culture were held at six cities in Shandong Province. Totaling about 185 , these sessions were grand in scope, rich in content, and diverse in form.

The Chinese Government and the Shandong Provincial Government attached great importance to the Jinan Congress and provided generous financial support for it. Vice Premier Liu Yandong attended the opening ceremony and read the Congratulatory Message from President Xi Jinping. Chinese historians agreed with what Xi said in the message, "Historical studies lay the foundation for all social sciences," which also conveyed the value that Chinese people have traditionally placed on historical study. Marjatta Hietala, President of the CISH, delivered the opening speech, in which she reviewed the process and channels of knowledge transmission and cultural communication between China and the world. She also outlined the role of the CISH in transnational cultural communication and responded to the challenges facing contemporary historians, such as competition, media, and the Internet. At the opening ceremony, professors and students from Shandong University performed traditional Chinese music, which was met with a standing ovation by Congress participants.

The theme of the Opening Speeches was "Nature and Human History." The Congress invited three distinguished scholars from Europe, Africa, and 
Asia to speak on this topic: Andrea Giardina (Italy), Mamadou Fall (Senegal), and Xia Mingfang (China). Having conducted research from different perspectives, the speakers elaborated upon the relationship between the environment and the development of human society.

Traditionally, the CISH designs the topics of the Major Themes to focus on the latest historical research trends; therefore, the Major Themes were given priority in scheduling - up to a single day for each theme - with top historians representing each field contributing their ideas. That the Congress was held in Jinan is witness to China's growing influence in recent years. That is also why the subject of Major Theme 1 was designated as "China from Global Perspectives." Major Theme 1 was organized by Wang Jianlang (Chinese Academy of Social Sciences) and María Dolores Elizalde (CSIC, Madrid) and discussed by Kenneth Pomeranz from the University of Chicago. Fourteen scholars from China, the US, France, Italy, Russia, Switzerland, Canada, Spain, Japan, and Bangladesh expressed their views on the connection and interaction between China and the world, the role China has played, and how much China has influenced the history of globalization since the $15^{\text {th }}$ century. The paper of Wan Ming (Chinese Academy of Social Sciences) indicated that the link between domestic and foreign markets was promoted and strengthened as a result of silver monetization in the Ming Dynasty, thereby facilitating China's participation in the early stages of globalization. Professor Paul A. Kramer from Vanderbilt University looked into the history of Chinese exclusion in the United States from 1868 to 1910. He focused on exceptions to anti-Chinese sentiment, finding that some Chinese in the welleducated elite class were actually welcomed in the US. Pierre Singaravélou (Université de Paris 1 Panthéon-Sorbonne) focused on Tianjin, the largest port city of northern China, describing the city as an energetic laboratory of globalization. Professor Kawashima Shin from the University of Tokyo discussed internationalism and nationalism in modern Chinese diplomatic history, and suggested that past evaluations of the tributary system were related to national humiliation in modern Chinese history.

Major Theme 2 centered on historicizing emotions. For the first time in the history of the Congress, research on emotional history was designated as a major theme. World historians showed great interest in the objects and methods of emotional history. Chaired by Ute Frevert and Andrew Lynch, 11 scholars from France, Britain, Germany, Australia, and other countries delivered speeches. This Major Theme included four sessions: "Emotions, Capitalism and the Market," "Emotions and the Creation of 'Others'," "Emotions in Bodies and Spaces," and "Historicizing Emotions: Theories and Methodologies." Attendees exchanged views in the fields of politics, economy, life, the art of music, and death. From the scholars' remarks, it is 
clear that there is increasing academic interest in the history of emotions. The research methodology of the history of emotions emphasizes interdisciplinary approaches including psychiatry, literature, economics, and business. Specialized research institutes have been established in Germany and Australia and publications in this field are growing. Does this indicate that an emotional turn has emerged in modern historical science? The Jinan Congress contributed to the promotion of emotional history studies, which is an interesting field deserving more attention and research.

Major Theme 3, "Revolutions in World History: Comparisons and Connections," was convened and hosted by Alan Forrest from the University of York, Mitani Hiroshi from the University of Tokyo, and Pierre Serna from Université Paris 1 Panthéon-Sorbonne. Anna-Maria Rao and Mitani Hiroshi commented on the speeches from 11 scholars. Four topics were covered in four sessions: "Revolutions in the Atlantic World," "Revolutions in Twentieth Century Europe," "Revolutions in Modern Africa and the Middle East," and "Revolutions in Modern East Asia." The scholars discussed revolutions in different regions. Scholars could compare and connect with each other using transnational perspectives; they came to enlightening conclusions thanks to these exchanges. Victoria Zhuravleva displayed political cartoons on the Russian revolution published in the US, using historical materials such as archives, books, and cartoons. Joanna De Groot compared indigenous and transnational elements in the Iranian revolutions of 1905-1911 and 19771982. Park Hun indicated that the Meiji Restoration should be re-conceptualized in the East Asia context, while attention should be given to the emergence of a "literati political culture." Wang Qisheng stated that the 1911 Republican Revolution, the Nationalist Revolution, and the Communist Revolution were three interlinked phases in the progressive trajectory of the Chinese revolution; each left enough room for the next revolution to advance on the basis of the previous one.

Major Theme 4, Digital Turn in History, was organized and reviewed by Tom Dublin from State University of New York. Twelve scholars delivered speeches during two sessions. The first session in the morning was "Digital History: Challenges and Possibilities." Incorporating the session topic of "challenges," scholars argued that the digital turn signifies that historians must confront the challenge of the internet, adapt to new approaches and to the construction of databases, and fully utilize them. Professor Serge Noiret, President of the International Federation for Public History, began his presentation by discussing the role digitization has played in the construction of the memory of public history. He appealed to historians to take part in this construction proactively. The second session in the afternoon focused on "New Tools, New Narratives, New Histories." Speakers at the session empha- 
sized the adaption and applications of new tools in historical research. The evening session was designed around the topic, "Promoting Digital History Internationally." The presenters intrigued and stimulated the audience by explaining how history is constructed. The Technology and Humanities Camp was a successful experiment that created new ways to make historical science available to the public. Major Theme 4, "Digital Turn" and "Big Data," reflected the themes of our era, and the fact that there is need for ongoing and profound research on their influence on historical science.

Owing to the scope of the conference, this author is not able to provide a more comprehensive introduction here to the Specialised Sessions, Joint Sessions, Round Tables, and sessions organized by International Affiliated Organizations. I will limit my discussion to my impressions of the Jinan Congress in general. Subjects of the papers were diverse, while their global or transnational perspectives showed the similarity of the attendees. This is what the ICHS has always encouraged in order to avoid conducting research that is too centered on the nation-state narration and to use global or transnational narratives instead. Some new subjects - or subjects that are new to some while familiar to others-were represented in the programme: the change of natural environment, the spread of species and technologies, the spread of infectious diseases, mass migration, empire expansion, transregional trade, and the transmission of religion and cultural ideas; all of the above global phenomena or processes were discussed at the Congress. In addition, traditional topics or approaches-national, regional, political, gender, labor, and public histories - were addressed from new perspectives of global history, and attracted the participation of many researchers. Reviewing how these sessions were organized or what the papers discussed, we could conclude that despite "global history" not being one of the major themes of the Jinan Congress, never have previous Congresses been characterized so much by "global history" or "globalization" as this one was.

Two new academic awards also stand out as special innovations of the Jinan Congress. One is the International Prize of History, the CISH/JaegerLeCoultre History Prize. This prize honors a historian who has distinguished himself or herself in the field of history by his or her works, publications or teaching, and has significantly contributed to the development of historical knowledge. There are no individual applications. Only the collective members of the CISH-its national committees or its international affiliated organizations - may present candidates and vote. The prize is sponsored by Swiss watch manufacturer Jaeger-LeCoultre. The first laureate of the prize, Serge Gruzinski (Senior Professor of the School of Advanced Studies of Social Sciences, Invited Professor of Princeton University) is a specialist on the history of Latin America in the $16^{\text {th }}-18^{\text {th }}$ centuries and a pioneer in the 
development of global history and transnational history, which currently represent the main trends in the historical sciences. Serge Gruzinski doesn't simply aim to de-westernize history; he wants to globalize it. If the world is to be taken globally, the approach has to be global, too. The issue is to examine how cultures and countries are brought into mutual contact, how they meet, face, and appreciate or dislike each other. In his latest book, "The Eagle and the Dragon: Globalization and European Dreams of Conquest in China and America in the Sixteenth Century," he states that the history of European expansion in the 15th and 16th centuries may be written in parallel with the history of success in America and failure in China. Actually, what we know about early globalization in the $16^{\text {th }}$ century is simple; only a global history is able to restore the historic landscape in all its depth, complexity, diversity, and ambiguity. Until the 19th century and often long after that, countries in the Americas were considered only as appendages, or as products or bad replicas of Western Europe. Serge Gruzinski has contributed significantly to profoundly rethinking this concept. The second award, the CISH-SDU prize, sponsored by Shandong University and proposed by its president, Zhang Rong, was established to cultivate and encourage the next generation of historians. Six PhD students from China, Germany, and Canada became the first laureates from more than seventy candidates in the General Poster Session. These two prizes will continue to be awarded regularly in later world Congresses.

Since China hosted the Congress, there was broader participation of Chinese historians and more dialogue between Chinese and non-Chinese historians than had ever been possible at previous Congresses. Of the many topics discussed at the Jinan Congress, ten were designed and recommended by the Association of Chinese Historians. Chinese scholars chaired 16 primary and affiliated sessions, and 80 Chinese scholars delivered speeches or served as discussants. The broad degree of participation by Chinese scholars in preparing for and attending the Jinan Congress far exceeded that of any previous Congress; this level of Chinese participation demonstrated the extraordinary achievements of Chinese historical studies in the last three decades. However, it cannot be denied that studies by Chinese historians in fields such as emotional history, the digital turn, and the theory of global history are still scant; also, Chinese scholars' competence in English and other foreign languages is lacking. The next ICHS (the $23^{\text {rd }}$ ) will be held in Poznan, Poland in 2020. This writer is looking forward to seeing more Chinese historians actively participate in the world Congress, communicate with scholars from around the world, and learn from each other to become more integrated with other historians in the ICHS, the "global community of historians" (Karl Dietrich Erdmann). 


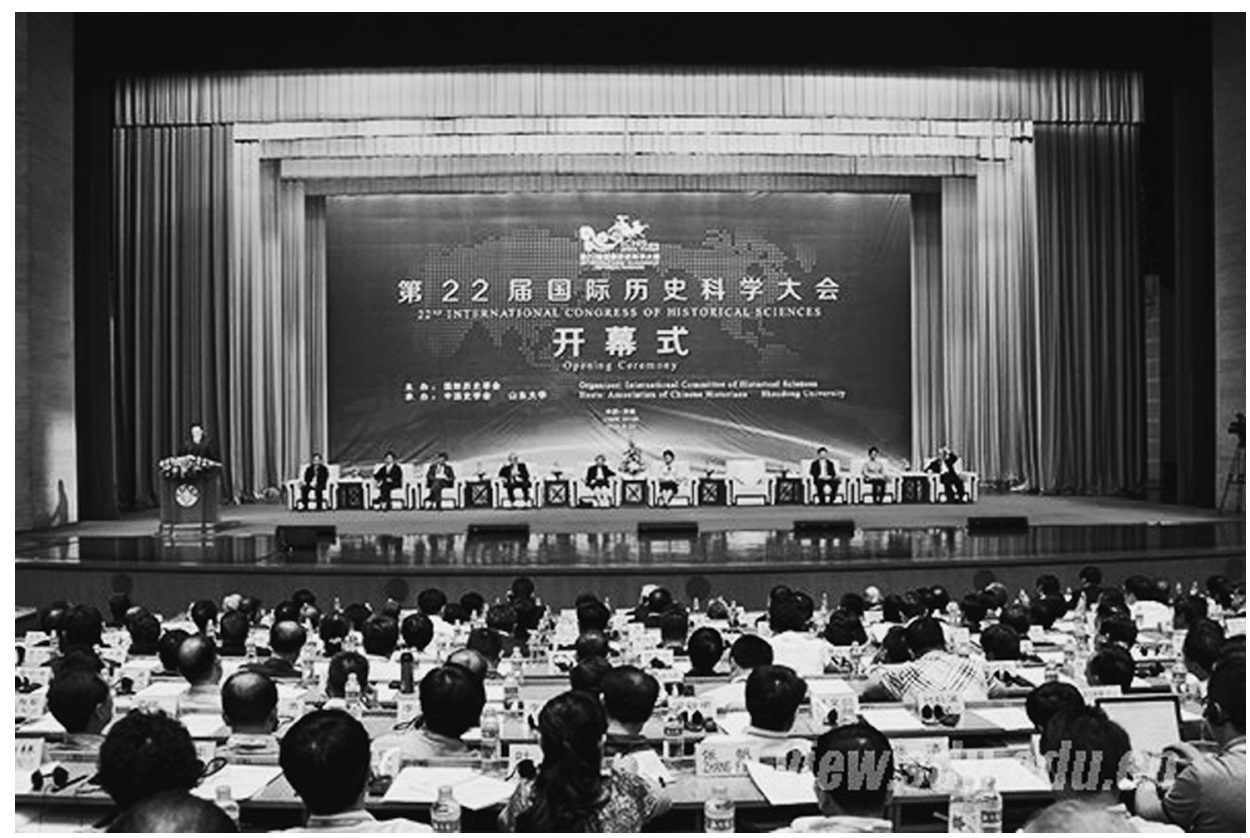

The opening ceremony of the 22nd International Congress of Historical Sciences Held in Jinan, China. Photo by Li Huayang

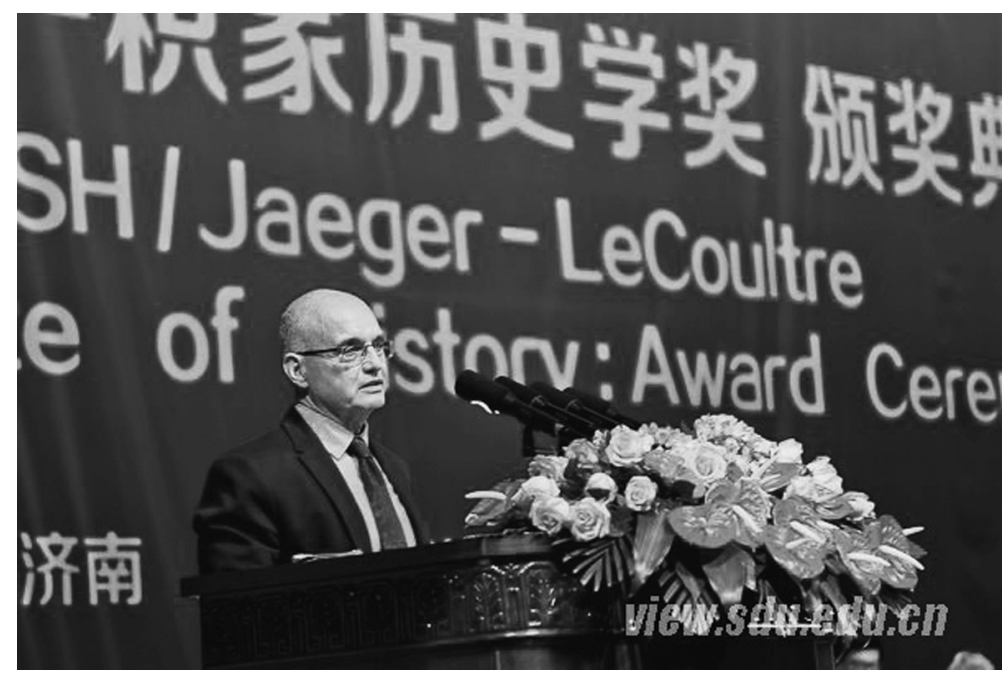

Professor Serge Gruzinski, the first winner of $\mathrm{CISH}$-Jaeger LeCoultre International History Award 